\title{
Design of a purchases and inventories management of a cleaning products distribute company
}

\author{
Rosita Cabrera $^{1}$, Jerson $\operatorname{Vargas}^{1}$, Miguel Shinno ${ }^{1}$, Fernando Maradiegue ${ }^{1}$ and José Álvarez ${ }^{1}$ \\ ${ }^{1}$ Ingeniería Industrial, Universidad Peruana de Ciencias Aplicadas, Perú, \\ u201415428@upc.edu.pe,u201214281@upc.edu.pe,pemshinn@upc.edu.pe,fmaradie@upc.edu.pe and pciijalv@upc.edu.pe
}

\begin{abstract}
The Company under study dedicated to the distribution of cleaning products has presented high operating costs resulting from a disorganized management in the processes of purchases and inventories. This is a problem that happens to many companies in the retail sector because, it does not have tools or controls that allow it to evaluate its development in such processes. To solve this problem, a management of purchases and inventories is proposed based on tools that involve the development of demand forecasting in order to be able to evaluate the trend and fluctuation of the demand, so that the company is prepared for any change. On the other hand, an ABC classification of products to be able to take into account those products that have a higher turnover. In addition, the development of economic lots, safety stocks and replenishment points to track inventories in the warehouse. Finally, an adequate control of the management by means of procedures, policies and formats that will allow a standardization and a correct flow of said processes. All this, in order to contribute to the reduction of operating costs and increase the utility of the company.

Keywords-- Inventories, distribution companies, demand management, ABC classification, supply logistics.
\end{abstract}

\section{INTRODUCTION}

The retail sector in Peru has had a growth of $12.6 \%$ since 2015 [1] due to the higher demand from consumers. Focusing on the retail sector; This is made up of small companies that seek to reach customers with a lower price than the competition. According to INEI statistics, it is expected that by the end of 2018 the sector in question will have a growth closure of 3.9\% of Internal Gross Product with respect to 2017 [2]. are:

The problems that companies in this sector go through

- The absence of strategic plans

- The lack of loyalty of recurrent customers

- And inefficient models that companies handle

These problems make companies not competitive with the current companies that arise over time. The company that will be analyzed is dedicated to the distribution of cleaning products characterized by fulfilling the orders received before or during the date assigned by the customer, but in this way towards the fulfillment with all the orders in time many errors and losses are observed for the company. In this sense, the money that is immobilized in storage, purchases from suppliers at a price higher than that established, breakages and

Digital Object Identifier (DOI):

http://dx.doi.org/10.18687/LACCEI2019.1.1.186

ISBN: 978-0-9993443-6-1 ISSN: 2414-6390 breakages of stock has had negative repercussions which is reflected in a decrease in the profitability of the company and therefore, a low competitiveness compared to emerging companies.

That is why, the problem identified is the inefficient supply management in the company, which directly impacts the costs of operations causing the decrease in the profitability of it. This inefficient supply management of the company generated in 2017 a loss of $12 \%$ of the total amount invoiced that same year, which was a significant amount for the company and even more so if the size of the company and the existing competition are considered.

The problem of the company under study is important because inefficient supply management in a company, regardless of the sector to which it belongs, generates significant economic losses, in this case an increase in operating costs. Likewise, it causes the company not to be at the same level as the competition, which directly affects its income, profit and profitability. The company during 2017 and the first quarter of 2018 has had a decrease in its profitability which did not allow them to invest in new expansion options or organizational growth.

\section{LITERATURE RESEARCH}

This point will cover the concepts and definitions of the main tools that will help solve the problem found in the company:

- Demand forecast

This tool is based on future sales projections according to the fluctuations of consumers or customers, since they are very uncertain and variable. However, the forecast will help to be prepared and take action and decisions at the moment. (two)

\section{- Purchasing management}

Purchasing management is responsible for supplying the materials in a continuous way in the commercialization process or production process. All this must be done efficiently to have the supplies at the exact time, exact amount, right place and with the right price. [3]. 
Part of purchasing management is the selection of suppliers where features such as price, quality, payment conditions, discounts, reliability, etc. are evaluated. The main criterion being the price because that is what will differentiate from other vendors. The search and selection of the best supplier is carried out by the purchasing department through certain procedures to evaluate and comply with the minimum characteristics according to the company's policy. [4].

\section{- Inventory management}

Inventory management aims to maintain enough stock to meet customer demand and has the purpose of determining the amount of inventory to maintain stock: how much to order and when to order [5]

On the one hand, there is the tool "ABC Classification" that can be integrated into the supply chain in order to achieve good results in terms of seeking to minimize the different costs associated with supply management and can be used in different approaches such as sales evaluation; products that generate higher profits, products with high levels of inventories represented economically. [6].

On the other hand, the tool of economic batch of purchases, is of important use for those companies that seek to minimize the levels of inventory and the costs associated with the purchases so that in this way a balance can be found between the orders and the operative costs. For this model you can apply the aggregation of products that can be a complete aggregation method that involves adding all the products in the same order so that each time an order arrives, it always contains all the products and the adaptive aggregation method involves identifying the product with the highest frequency of orders and then adjusting, in each order, a set of products. Therefore, each time an order arrives, it may not necessarily contain all the products. [7].

\section{STATE OF THE ART}

In relation to background, a first paper [8] has as its contribution the presentation of a basic nonlinear complete model with binary variables, and with a flexible structure that allows minor modifications to adapt to individual situations, this is a metaheuristic application model, using algorithms, the study was carried out with a sample of 50 products. Positive results were obtained such as: cost reduction, determination of economic lots, security stock, determination of prices as break points and security stock.

A second study paper [9] refers to a case study of different inventory controls in which they developed four different techniques for the efficient inventory management system of a Bangladeshi retail store.
As conclusion of the same, it is demonstrated with the case in study applied in a company in real situation, that techniques belonging to the management of inventories achieve a benefit for the company in terms of cost reduction and improvement of profitability.

In the third paper of study [10] as a contribution presents, the cooperation between retailers and suppliers, and increase significant benefits, such as the reduction of the forecast error, a better allocation of resources. In addition, to improve the relationship between the customer and the outside, CPFR can also improve profitability, reduce inventory, cycle times and exhaustion situations, provide more efficient transportation planning and better promotional planning, etc.

In [11], they managed to reduce the amount of inventory of the retailer, but also increase the sales of the supplier and improve the performance and efficiency of the entire supply chain.

\section{METHODOLOGY}

The present academic study has as a research methodology a quantitative as well as a qualitative analysis. First, for the diagnosis, an analysis and taking of current data was carried out in which the surveys were carried out as a qualitative basis for both the operative and administrative personnel to identify the problem, later it was made based on the Vester tool the identified problems in the company in order to determine the main problem. Once the main problem is determined, the necessary data are taken in order to quantify the problem. Then we proceeded to analyze the different causes that generated the problem in order to determine the main causes. All this, using tools such as problem tree, Ishikawa, weighting and paretos charts. Once the results have been obtained as a situation before the implementation, values records are taken. In what corresponds to the proposal, a general outline of those relevant tools that are aligned with the solution of causes was made; second, a logical order is made for the development of the tools since some of them depend on previous results. As a third step, the implementation of the proposal to be used is broken down in phases, being classified as follows:

$17^{\text {th }}$ LACCEI International Multi-Conference for Engineering, Education, and Technology: "Industry, Innovation, And Infrastructure for Sustainable Cities and Communities", 24-26 July 2019, Jamaica. 


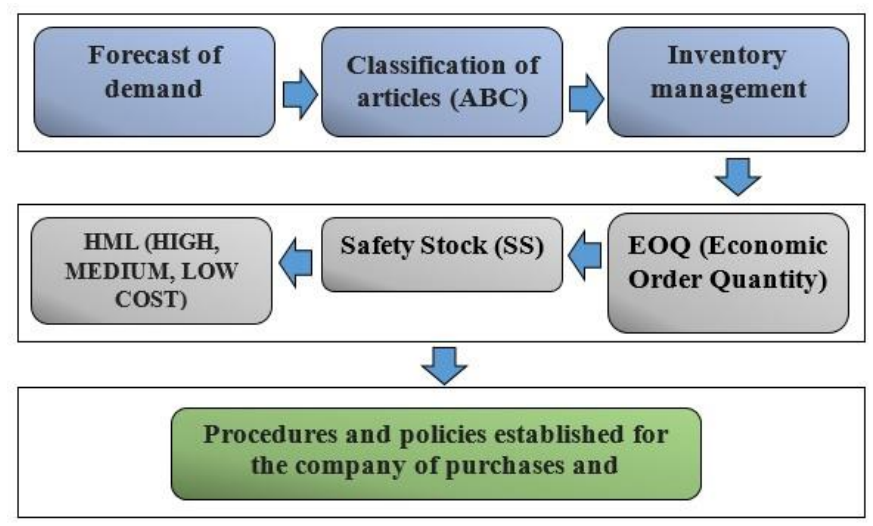

Fig. 1. Tool making sequence

- Phase I: Corresponding to the development of $\mathrm{ABC}$ classification based on criteria of: frequency of sales, contribution margin, existing inventory and multicriteria evaluation.

- Phase II: Demand forecasts, execution of forecast types such as double mobile, exponential attenuation of 2 and 3 parameters.

- Phase III: Inventory management, development of tools such as economic lot, security stocks, HML analysis and replacement point.

- Phase IV: Procedures, policies and formats for the adequate sustainability of the established processes.

Once each phase has been completed, the simulation pilot is carried out to obtain the data after the execution of the proposal for the respective improvement analysis. In what corresponds to the simulation, from the historical data of the demand, we proceeded to run in 3 different software: Minitab, NumXL and SPSS Statistics of the first two were to be able to determine the best program with a smaller error in the results obtained for the forecasts, resembling the reality and the third program was used for the validation of the results obtained by the Cronbach alpha coefficient. These programs have specific entries that allow the entry of real data or variants that may be affected to them as obtaining scenarios.

\section{RESULT}

\section{A. Results before the intervention}

It identifies that situation that generates negative economic impact in the organization, this with the purpose of being able to apply the different engineering tools to find the root cause that generates it and determine the most feasible solution.
To do this, identify the problems that currently exist in the company under study, then using a scale of values between 0 and 5, with 0 being less shocking and 5 more impacting, adding the scores obtained and making a double-entry matrix. in which the problems are confronted in parallel as detailed in table 1. These results are captured in a Cartesian plane of results with their values corresponding to the axes of assets (x) and liabilities (y) to finally graph them in the Cartesian plane figure 1 and define the problems to attack that, in this case covers purchases and inventories since these are in the critical problems quadrant as shown.

TABLE I

PROBLEMS OF THE COMPANY

\begin{tabular}{|l|l|}
\hline ITEM & PROBLEMS \\
\hline P1 & Objectives independent of the areas \\
\hline P2 & Cost overruns in purchases \\
\hline P3 & Workers without training \\
\hline P4 & Lack of planning of resources \\
\hline P5 & High cost of inventories \\
\hline P6 & The procedures are not mapped \\
\hline P7 & Bad distribution of plant \\
\hline
\end{tabular}

a. Own elaboration based on the current situation of the company under study

TABLE II

ESCALE OF MEASUREMENT OF ANALYSIS

\begin{tabular}{|l|l|}
\hline \multicolumn{2}{|l|}{ MESUREMENT SCALE } \\
\hline Does not influence & 0 \\
\hline Low & 1 \\
\hline Half & 2 \\
\hline High & 3 \\
\hline
\end{tabular}

b. Own elaboration based on the current situation of the company under study

$17^{\text {th }}$ LACCEI International Multi-Conference for Engineering, Education, and Technology: "Industry, Innovation, And Infrastructure for Sustainable Cities and Communities", 24-26 July 2019, Jamaica. 


\begin{tabular}{|c|c|c|c|c|c|c|c|c|}
\hline & P1 & P2 & P3 & P4 & P5 & P6 & P7 & $\begin{array}{c}\text { Total } \\
\text { Active }\end{array}$ \\
\hline P1 & & 2 & 0 & 2 & 3 & 1 & 1 & 9 \\
\hline P2 & 3 & & 3 & 3 & 3 & 2 & 1 & 15 \\
\hline P3 & 1 & 3 & & 1 & 2 & 1 & 1 & 9 \\
\hline P4 & 2 & 2 & 1 & & 2 & 1 & 1 & 9 \\
\hline P5 & 3 & 3 & 2 & 2 & & 3 & 2 & 15 \\
\hline P6 & 2 & 2 & 1 & 2 & 2 & & 1 & 10 \\
\hline P7 & 1 & 3 & 1 & 1 & 1 & 1 & & 8 \\
\hline $\begin{array}{c}\text { Total } \\
\text { Passive }\end{array}$ & 12 & 15 & 8 & 11 & 13 & 9 & 7 & \\
\hline
\end{tabular}

Own elaboration based on the current situation of the company under study

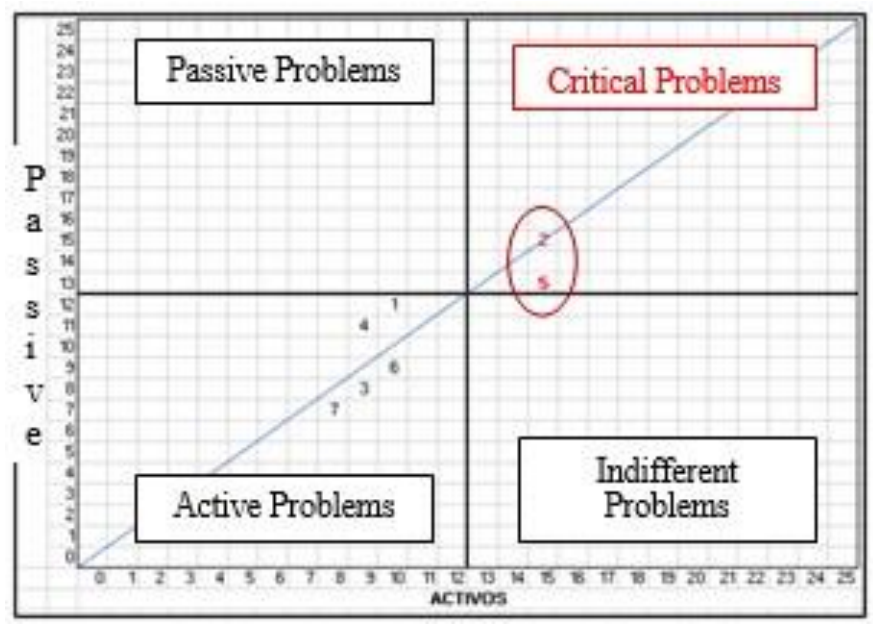

Fig. 2. Graphical matrix Vester

Once the problem is identified, the Ishikawa diagram is made to identify the root causes of the problem and to corroborate the relationship of the causes with the problem a correlation of variables is made and if this marks points close to the line corroborates the relationship of the causes and the problem.

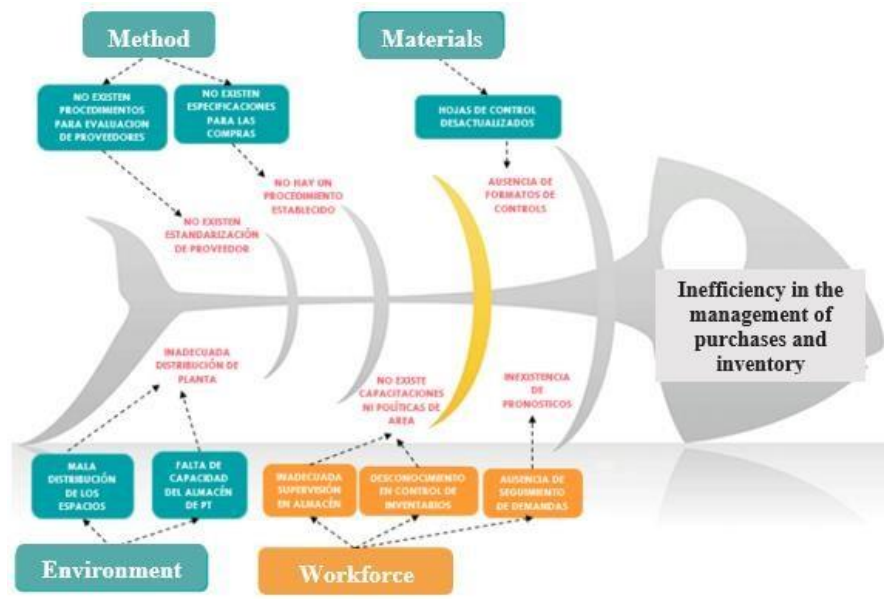

Fig. 3. Ishikawa diagram to identify the root causes of the problem.

On the one hand, the inventory rotation handled is inadequate since, after an analysis of the $\mathrm{ABC}$ classification of the products evaluated (55) resulted in an inefficient inventory rotation as shown in (2).

It should be noted that the classification products A are rated to have a higher turnover, that is, their flow of movement is continuous, therefore it should result in an index higher than the others, classification B have an intermediate movement flow, this value should be less to classification $\mathrm{A}$, but greater than $\mathrm{C}$ and, finally, classification $\mathrm{C}$ its rotation is minimal, with a value less than $\mathrm{A}$ and $\mathrm{B}$.

TABLE IV

COMPARISON OF ROI OF 3 RATINGS

\begin{tabular}{|c|c|}
\hline Classification & Total ROI \\
\hline A & 47 \\
\hline B & 48 \\
\hline C & 22 \\
\hline
\end{tabular}

Own elaboration based on the current situation of the company under study

On the other hand, the company makes purchases by estimates without prior calculation which means that several times do not have stock availability to fulfill the customer order. Seeking to fulfill the order on time they request an urgent order the usual provider, but this does not have availability and choose to buy from another provider at a higher cost. This occurrence is called the high purchase cost, which represents $9 \%$ of the economic impact lost in 2017.

Also observed products that were already expired, outdated or products that were in the warehouse for several months without having any movement which have a result of $34 \%$ of economic impact with respect to the total loss of the year 2017.

TABLE V

PERCENTAGE IMPACT WITH REGARD TO THE TOTAL OF LOST 2017

\begin{tabular}{|l|c|}
\hline & Current \\
\hline Rupture of Stock & $17 \%$ \\
\hline Cost of over Stock & $40 \%$ \\
\hline Fixed Stock & $10 \%$ \\
\hline High cost of purchcase & $34 \%$ \\
\hline Total Economic Impact & $100 \%$ \\
\hline
\end{tabular}

Own elaboration based on the current situation of the company under study

Figure 4 shows the trend of the utility of the company during the year 2017, which were decreasing with the passage

$17^{\text {th }}$ LACCEI International Multi-Conference for Engineering, Education, and Technology: "Industry, Innovation, And Infrastructure for Sustainable Cities and Communities", 24-26 July 2019, Jamaica. 
of time. Also, in figure 4 it is observed that, when there are periods with an increase in demand, the company does not it is supplied because, its existing inventories levels do not meet demand, therefore, the inventory trend is below the upper range of sales in the months of November 2017 to May 2018.

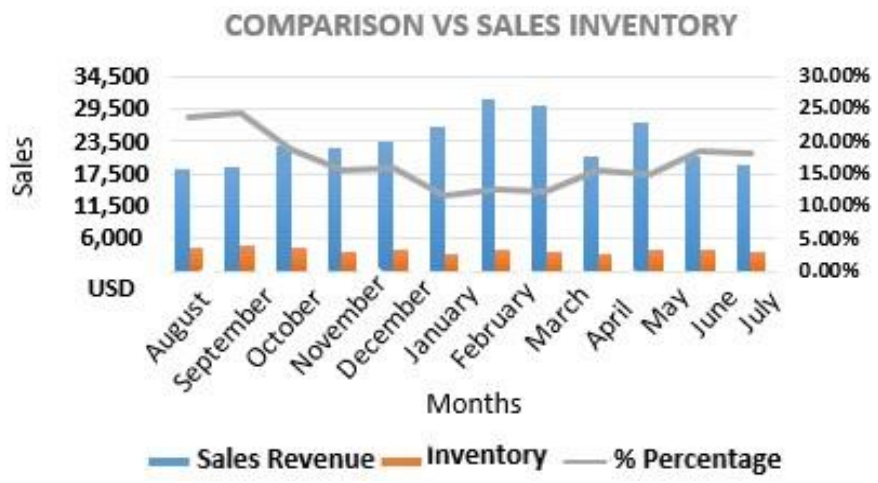

Fig. 4. Trend of sales with operational utility revenues

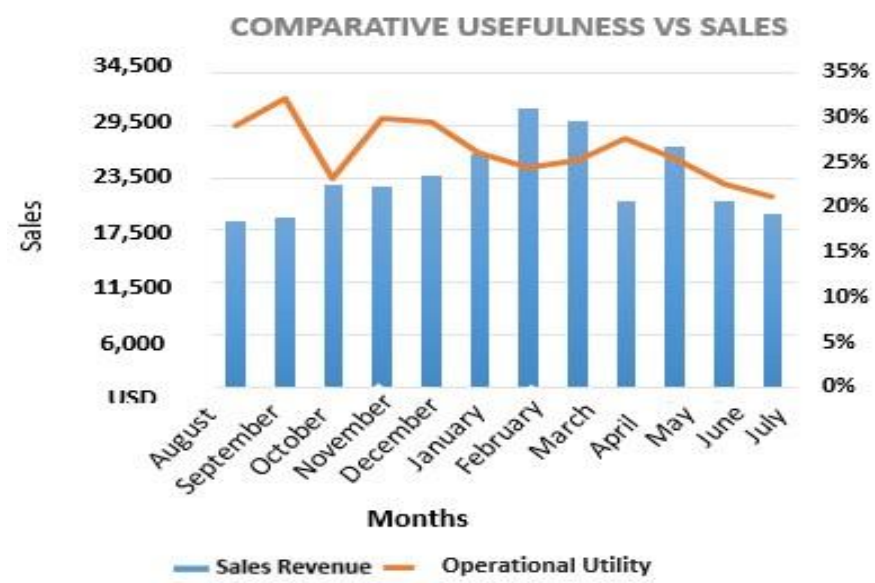

Fig. 5. Fluctuation of inventories to sales.

After the analysis developed, the following is shown:

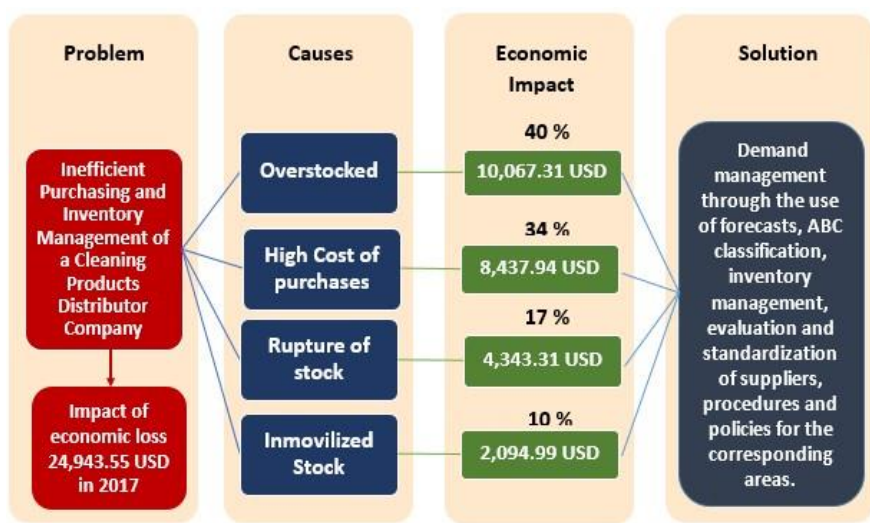

Fig. 6. Causes of the problem and its economic impact summary
The model developed in the present research project is shown in figure 7.

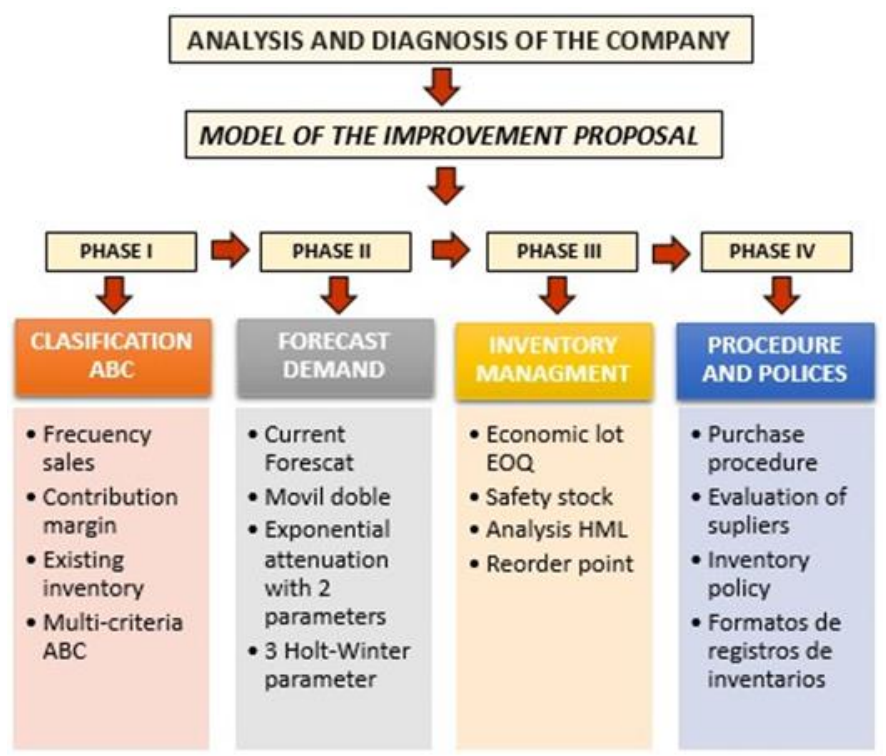

Fig. 7. Model input sequence

The first step is an analysis and diagnosis of the company in order to find the main problem and the causes that generate it and at the same time the economic repercussions that it has. After that, the model broken down into phases is applied.

In phase I, everything about the $\mathrm{ABC}$ classification will be developed, which involves 4 different classification distributions: (i) according to the frequency of sales, (ii) according to the margin of contribution, (iii) according to the existing inventory and (iv) by multicriteria. All this in order to be able to evaluate the similarity or difference of the products that are according to the type of classification.

\begin{tabular}{|c|c|c|c|}
\hline CLASSIFICATION & SALES & $\begin{array}{c}\text { CONTRIBUTION } \\
\text { MARGIN }\end{array}$ & STOCK \\
\hline A & $76 \%$ & $83 \%$ & $75 \%$ \\
\hline B & $17 \%$ & $9 \%$ & $14 \%$ \\
\hline C & $7 \%$ & $8 \%$ & $11 \%$ \\
\hline
\end{tabular}

Fig. 8 Values of abc classification types

In phase II, everything about forecasting the demand will be developed, taking into account a previous analysis of different types of forecast models in order to be able to determine the one with the lowest error, which would mean that the predicted value is the more similar to reality.

B. Innovative technical proposal

$17^{\text {th }}$ LACCEI International Multi-Conference for Engineering, Education, and Technology: "Industry, Innovation, And Infrastructure for Sustainable Cities and Communities", 24-26 July 2019, Jamaica. 


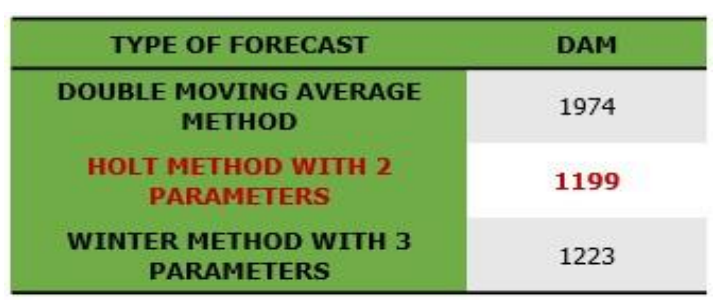

Fig. 9 Types of forecasting results

In Phase III, everything related to inventory management will be executed. Tools such as economic batches, security stocks, reorder point and HML analysis (the initials corresponding to $\mathrm{H}=\mathrm{High}, \mathrm{M}=$ Medium and $\mathrm{L}=\mathrm{Low}$ ). In order to be able to have exact values when making purchases and evaluate the costs of the different products. It should be noted that for the present evaluation each of these tools was developed for a sample of 55 since the company manages more than 100 items.

\begin{tabular}{|c|c|c|c|}
\hline CRITERION & PRODUCTS & $\begin{array}{c}\text { UNITARY COST } \\
\text { AVERAGE USD }\end{array}$ & $\begin{array}{c}\text { RANGES } \\
\text { (USD) }\end{array}$ \\
\hline $\mathrm{H}$ & 19 & 7.07 & $1.82-48.48$ \\
\hline $\mathrm{M}$ & 21 & 1.28 & $0.91-1.82$ \\
\hline $\mathrm{L}$ & 15 & 0.58 & $0.24-0.91$ \\
\hline
\end{tabular}

Fig. 10 Classification HML

Finally, in Phase IV everything related to the control of the different tools used in this proposal is involved. This implies the development of purchasing and inventory procedures, inventory policies, formats and supplier evaluation. All this in order to maintain the organization and sustainability of our proposal and that the company verifies the changes in its improvement.

\section{Results after implementation}

The model proposal that has been developed is implemented through a pilot in order to evaluate the trend of the results obtained with the improvement through a program or system of manual and systematized calculations. And the simulation of it is done in an office - Excel program that has as an extension an extension called NumXL (Figure 11) with which data is obtained for the forecasted demand, this program has the function of optimizing the forecast parameters in order to reduce the margins of errors regarding a manual forecast so that, in this way, the results obtained are the closest to reality. In addition, a simulation forecast was also developed in the SPSS minitab to verify comparative data, in this way the first simulator was the most optimal. And finally, a data validation was performed with Cronbach's alpha to determine that the results are valid with a coefficient greater than 0.5 (Figure 12).

The results are appreciated below.
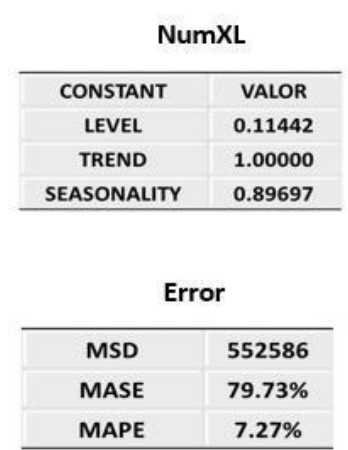

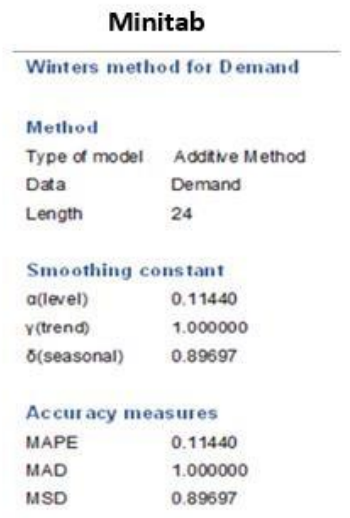

\begin{tabular}{|c|c|c|}
\hline Software & $\begin{array}{c}\text { Mean Absolute } \\
\text { Percentage Error }\end{array}$ & Mean Square Error \\
\hline NumXL & $7.27 \%$ & 552586 \\
\hline Minitab & $11 \%$ & 1019402 \\
\hline
\end{tabular}

Fig. 11 Comparison of simulators

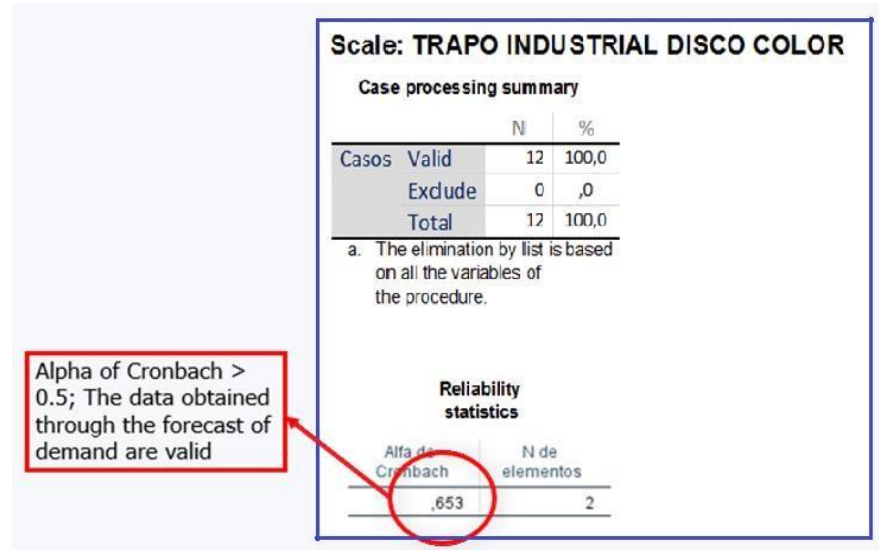

Fig. 12 Cronbach's alpha data validation

VI. ANALYSIS OF RESULTS

At this point the previous results are compared; that is, that obtained with the diagnosis before the implementation proposal and the results obtained and obtainable with the pilot and the simulation.

\begin{tabular}{|c|c|c|c|c|c|}
\hline & \multicolumn{2}{|c|}{ CURRENT } & \multicolumn{2}{|c|}{ IMPROVEMENT } & REDUCTION \\
\hline OPPORTUNITY COST & $\$$ & $4,447.88$ & $\$$ & $2,266.67$ & \multirow{5}{*}{$60.0 \%$} \\
\hline OVER STOCK COST & $\$$ & $34,022.00$ & $\$$ & $3,905.45$ & \\
\hline IMMOBILIZED STOCK & $\$$ & $10,309.70$ & $\$$ & $4,049.70$ & \\
\hline HIGH COST OF PURCHASES & $\$$ & $2,145.45$ & $\$$ & $\cdot$ & \\
\hline OVERHEADS & $\$$ & $25,544.24$ & $\$$ & $10,221.82$ & \\
\hline
\end{tabular}

Fig. 13 Impact economic as registry

$17^{\text {th }}$ LACCEI International Multi-Conference for Engineering, Education, and Technology: "Industry, Innovation, And Infrastructure for Sustainable Cities and Communities", 24-26 July 2019, Jamaica. 


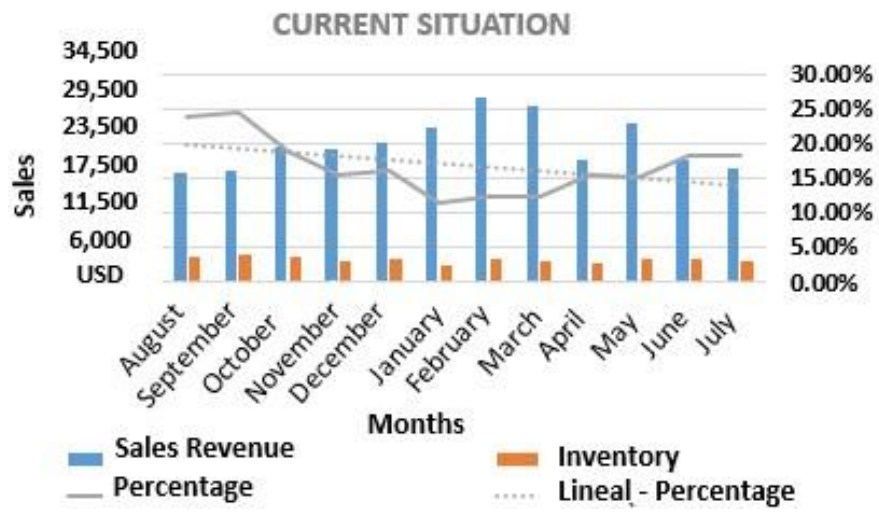

Fig. 14 Inventory without improving level

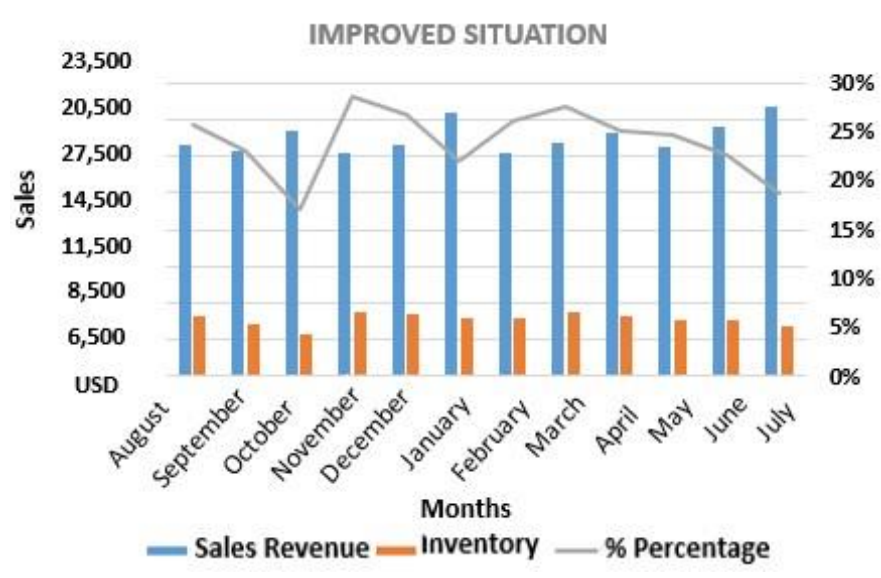

Fig. 15 Improved inventory level

\section{CONCLUSIONS}

In conclusion, the problem that is evident in the company is the inefficient management of supply which generates a loss of profitability due to over stock in warehouses, stock breakages, high purchase costs and immobilized stock. The improvement proposal deals with the design and implementation of a supply system to reduce the company operating costs. For this purpose, the system proposes the improvement of the purchasing and inventory processes where it implemented demand planning, the evaluation and

standardization of suppliers, a purchasing management policy is established and an existence control policy is implemented. The present project achieves a total reduction of up to $60 \%$ broken down in opportunity cost from $17.41 \%$ to $8.87 \%$, cost of over stock from $40.36 \%$ to $15.29 \%$, from an initial indicator of immobilized stock from $33.83 \%$ to $15.56 \%$ and finally in terms of the high cost of purchases there was a total reduction of $8 \%$ to $0 \%$ as unexpected purchases are avoided causing costs outside of budget. On the other hand, the indicators of product rotation are stabilized according to their classification (A, B, C) so that in this way there are forecasts regarding the purchases necessary for the supply of products as a first need according to its degree of importance. In addition, according to financial evaluations it was obtained that the project is profitable with a Current Net Value greater than 0 and a time 95 days investment recovery.

\section{RECOMMENDATIONS}

It is recommended to carry out a mapping of the process of the areas of improvement and in this way it will be possible to identify in a simple way the process in the base of the activities to improve and review the documentation and the established formats. The dissemination and updating of policies and procedures established in the areas. On the other hand, keep an exact record of the demand, and the analysis of its variability, in order to preserve the levels of existence of the relevant products in the warehouse. Update the $\mathrm{ABC}$ classification of the inventory since they have repercussions in the demand and in the models made for forecasting. The implementation of more sophisticated software for inventory tracking and tracking can provide support variables for the best decisions in the process. The reference to lower costs refers to price indicators and suppliers to compare monthly costs and avoid cost overruns and investment losses.

\section{REFERENCES}

[1] G. Secco, The Supply Chain. Obtenido de Logistica360, Lima, 2018.

[2] Instituto Nacional de Estadística e Informática, «INFORME TÉCNICO Produccion Nacional,» Lima, 2018.

[3] H. G. C. Valdecy Pereira, «A multiproduct economic order quantity model with simulated annealing,» Emeraldinsight, vol. Vol. 12, pp. pp.119-142, 2017.

[4] A. H. Niknamfar, «Multi-objective production-distribution planning based on vendor-managed inventory strategy in a supply chain,» Industrial Management \& Data Systems, vol. Vol. 115, pp. pp.10861112, 2015.

[5] J. B. Erik Hofmann, «Supply chain management and activity-based costing: current status and directions for the future,» International Journal of Physical Distribution \& Logistics Management, 2017.

[6] Ballou, R. H. (2004). Logística: administración de la cadena de suministro. Naucalpan de Juárez: Pearson Educación.

[7] Ávila, I. M. (2015). LA INNOVACIÓN EN LA EMPRESA A TRAVÉS DEL ABASTECIMIENTO ESTRATÉGICO. Gestión y estrategia, 93106.

[8] Darya Plinere, A. B. (2015). Case Study on Inventory Management Improvement. Information Technology and Management Science.

[9] Erik Hofmann, J. B. (2017). Supply chain management and activitybased costing: current status and directions for the. International Journal of Physical Distribution \& Logistics Management.

[10] Valdecy Pereira, H. G. (2017). A multiproduct economic order quantity model with simulated annealing application. Journal of Modelling in Management, 119-142.

[11] R. Zare, P. Chavez, C. Raymundo, J. Rojas, "Collaborative Culture Management Model to Improve the Performence in the Inventory Management of a Supply Chain", 2018 Congreso Internacional de

$17^{\text {th }}$ LACCEI International Multi-Conference for Engineering, Education, and Technology: "Industry, Innovation, And 
Innovacion y Tendencias en Ingenieria, CONIITI 2018 - Proceedings 8587073.

$17^{\text {th }}$ LACCEI International Multi-Conference for Engineering, Education, and Technology: "Industry, Innovation, And Infrastructure for Sustainable Cities and Communities", 24-26 July 2019, Jamaica. 